\title{
Production of nanostructured $\gamma$-alumina from aluminum foundry tailing for catalytic applications
}

\author{
Mostafa Mahinroosta $^{1} \cdot$ Ali Allahverdi $^{1}$
}

Received: 19 October 2017 / Accepted: 14 August 2018 / Published online: 23 August 2018

(c) The Author(s) 2018

\begin{abstract}
Aluminum production industry tailings are considered as hazardous solid wastes accompanied by a variety of serious disposal, environmental, and public health issues. This study is devoted to presenting a promising solution for dealing with such problems. Within the scope of the present study, synthesis of nanostructured $\gamma$-alumina from aluminum foundry tailing using a novel process was presented. The proposed process will provide a multilateral advantage to both environment and industries. Firstly, the amount of tailing and accordingly, disposal cost could be partly lessened; secondly, the environmental pollution can be reduced, and finally, if possible, green production of advanced materials from this kind of waste at a rational expense can bring about the conservation of natural sources and also gain economic benefits. Characterization of the as-synthesized products was performed using X-ray diffractometry (XRD), X-ray fluorescence (XRF), Fourier-transform infrared (FTIR) spectroscopy, field-emission scanning electron microscopy (FESEM) and transmission electron microscopy (TEM), energy dispersive X-ray spectroscopy (EDAX), and dynamic light scattering (DLS) for crystalline phase analysis, chemical composition, chemical bond recognition, morphology, elemental analysis, and particle size distribution, respectively. The chemical composition analyzed by XRF indicated that the as-synthesized alumina exhibits a purity of more than $97 \mathrm{wt} \%$. The XRD pattern majorly possessed characteristic peaks related to the gamma phase of alumina. Microstructural analyses by FESEM and TEM confirmed the nano-sized morphology of the as-synthesized $\gamma$-alumina.
\end{abstract}

Keywords Gamma-alumina $\cdot$ Nanostructure $\cdot$ Aluminum foundry tailing $\cdot$ Catalyst $\cdot$ Extraction

\section{Introduction}

Generally speaking, industrial development is accompanied by serious problems such as the release of large amounts of waste into the environment and depletion of natural resources. Therefore, the safe disposal of wastes and their respective costs have caused critical challenges for various industries [1]. Industrial wastes are accumulated over time, resulting in environmental and public health problems. For example, when the solid waste particles are dispersed in the air, breathing them could cause pulmonary diseases. Toxic and flammable

Ali Allahverdi

ali.allahverdi@iust.ac.ir

Mostafa Mahinroosta

m_mahinroosta@chemeng.iust.ac.ir

1 Research Laboratory of Inorganic Chemical Process Technologies, School of Chemical Engineering, Iran University of Science and Technology, Narmak,

Tehran 1684613114, Iran gasses produced from the accumulated wastes which are freely released in ambient air can be undoubtedly dangerous. Hence, some kinds of these wastes are considered as hazardous wastes according to environmental regulations. In addition, the generated amount of wastes undergoes an incremental trend yearly, making the above-mentioned concerns more challenging. Typically, a large portion of these wastes are disposed in dump sites. Consequently, the harmful substances leak into the surface and groundwater over time under different weather conditions like rain. As a result, water contamination can raise a variety of diseases such as Alzheimer's, skin irritation, and pulmonary-related disorders. Furthermore, uncontrolled waste disposal leads to the loss of the remaining valuable materials in the composition of the waste. For the reasons mentioned above, many researchers are looking for appropriate solutions, especially green approaches, to retrieve the remaining valuable components and to eliminate or reduce the accumulation of such detrimental substances [2-4]. On the other hand, with increasing demand for valuable materials such as nanomaterials, strict environmental laws and regulations, sustainable 
production, recycling, and waste management have been converted into important research fields [5, 6]. As a consequence of such concerns, 'green' synthesis has been worthy of great importance for a sustainable and safe generation of nanomaterials [7]. Many green synthetic methods have been developed for the synthesis of nanoparticles using bio and secondary sources [8-12].

Retrieval of wastes to form value-added products is an appropriate approach for both industries and the environment [13]. Aluminum foundry tailing (AFT) is a hazardous solid waste produced during aluminum smelting process which is aluminum oxide-rich $[14,15]$. The researchers have proposed some processes for extracting alumina from the solid wastes such as the acid-base leaching $[15,16]$, limestone sintering method [16], and lime-soda sinter method [5]. Alumina in nano-scale exhibits better catalytic and adsorption properties than its micro-sized form. Among the various forms of alumina, $\gamma$-alumina is a porous material which is distinctively known for its high specific surface area and good reactivity [17-21]. If the catalytic applications in heterogeneous reactions are the main goal, then, the surface area of the catalyst/ support becomes a vital characteristic. In this regard, nanostructured $\gamma$-alumina will exhibit a dramatic specific surface area, high mechanical, chemical and thermal stabilities, and low modification temperature as well [22, 23]. For these reasons, nanostructured alumina is synthesized from different methods including mechano-chemical [24], hydrothermal [25], sol-gel [26], precipitation [27], combustion synthesis [28], wire explosion [29], and chemical vapor deposition [30]. The aim of this work is to synthesize $\gamma$-alumina from hazardous AFT through a novel hydrometallurgy-based method and characterize it using advanced techniques.

\section{Experimental procedure}

\section{Materials}

Aluminum foundry tailing (AFT) was provided by an aluminum company located in Arak city, Iran.

To perform the extraction process, hydrochloric acid 37\%, ammonia $25 \%$, and sodium hydroxide (99\% purity) were purchased from Merck (Darmstadt, Germany) and ammonium nitrate (99\% purity) was supplied by Sigma-Aldrich (United States). All chemicals were used without any additional purification. Distilled water was used at all stages of the experiment.

\section{Characterization techniques}

The purity of the as-synthesized $\gamma$-alumina was found using ED 2000 X-ray fluorescence (XRF) analyzer (Oxford, England). The crystalline phases were characterized with a Philips PW 1800 powder $\mathrm{X}$-ray diffractometer using $\mathrm{Cu} \mathrm{K} \alpha$ radiation at $40 \mathrm{kV}$ and $30 \mathrm{~mA}$. The X-ray diffraction (XRD) patterns were recorded at a scanning rate of $1 \% \mathrm{~min}$ from $2 \theta=4^{\circ}$ to $80^{\circ}$. Fourier-transform infrared spectroscopy (FTIRs) was done using a SHIMADZU (IR Spectrophotometer $8400 \mathrm{~s}$ ) FTIR spectrometer in transmittance mode from 400 to $4000 \mathrm{~cm}^{-1}$. All spectra were obtained with a sensitivity of $4 \mathrm{~cm}^{-1}$ and 64 scans per spectrum was taken. Morphological studies were performed using SIGMA VP-500 FESE microscope (ZEISS) at an accelerating voltage of $15 \mathrm{kV}$. For this purpose, samples were first washed with a mixture of ethanol and distilled water and then dried in an oven at $110^{\circ} \mathrm{C}$ for $2 \mathrm{~h}$. The dried samples were placed on a holder using carbon adhesive and then coated with a thin gold layer to be conductive. Elemental analysis was carried out using Energy Dispersive X-ray Spectroscopy (EDAX) probe (Oxford Instrument, England). TEM analysis was performed using PHILIPS CEM12 microscope at operating voltage and vacuum pressure of $120 \mathrm{kV}$ and $10^{-6} \mathrm{~Pa}$, respectively. Dynamic light scattering (DLS) technique was employed using Scatteroscope I device to determine the particle size distribution of the as-synthesized alumina.

\section{Results and discussion}

Table 1 presents the chemical composition (determined by X-ray fluorescence XRF) of the AFT. The results of the chemical analysis show that the AFT contains a high percentage of aluminum oxide.

The mineralogical phases of the AFT were investigated by XRD technique. Figure 1 shows the XRD pattern of the AFT.

According to Fig. 1, the detected crystalline phases are corundum $\left(\alpha-\mathrm{Al}_{2} \mathrm{O}_{3}\right)$, graphite, fluorite $\left(\mathrm{CaF}_{2}\right)$, halite $(\mathrm{NaCl})$, quartz $\left(\mathrm{SiO}_{2}\right)$, spinel $\left(\mathrm{MgAl}_{2} \mathrm{O}_{4}\right)$, villiaumite $(\mathrm{NaF})$, and diaoyudaoite $\left(\mathrm{NaAl}_{11} \mathrm{O}_{17}\right)$.

To obtain the AFT particle size distribution, standard wire sieves were used according to ASTM standard E11. Figure 2 shows the results of the particle size analysis of the AFT. The $D_{50}$ as median value shows that half of the AFT particles are above $313.8 \mu \mathrm{m}$, and the rest below this point.

Figure 3 shows the process for extracting alumina from the AFT involving sieving, washing, leaching, filtration,
Table 1 Chemical composition of AFT

\begin{tabular}{llllllllllll}
\hline Oxide & $\mathrm{Al}_{2} \mathrm{O}_{3}$ & $\mathrm{SiO}_{2}$ & $\mathrm{CaO}$ & $\mathrm{Fe}_{2} \mathrm{O}_{3}$ & $\mathrm{MgO}$ & $\mathrm{SO}_{3}$ & $\mathrm{~K}_{2} \mathrm{O}$ & $\mathrm{Na}_{2} \mathrm{O}$ & $\mathrm{TiO}_{2}$ & $\mathrm{MnO}$ & $\mathrm{LOI}$ \\
\hline $\mathrm{Wt} \%$ & 61.74 & 14.96 & 2.56 & 4.42 & 2.56 & 0.17 & 0.86 & 2.85 & 0.32 & 0.30 & 10.41 \\
\hline
\end{tabular}




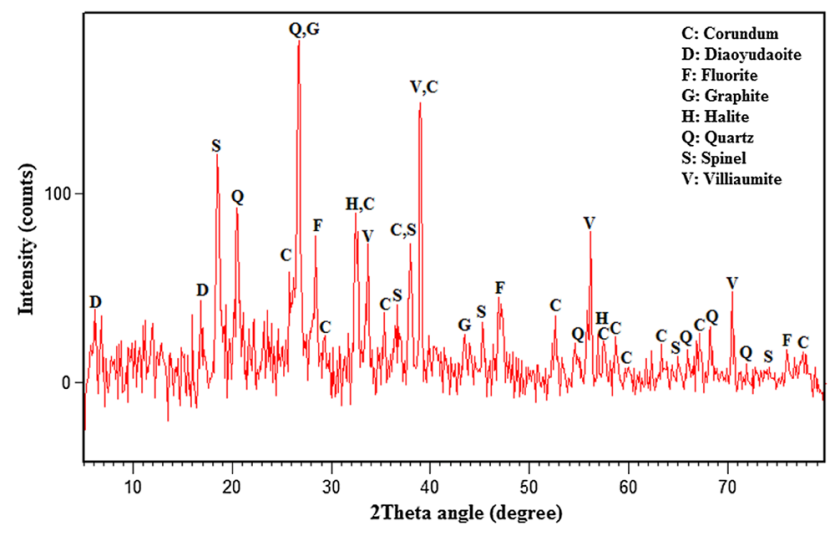

Fig. 1 XRD pattern of aluminum foundry tailing

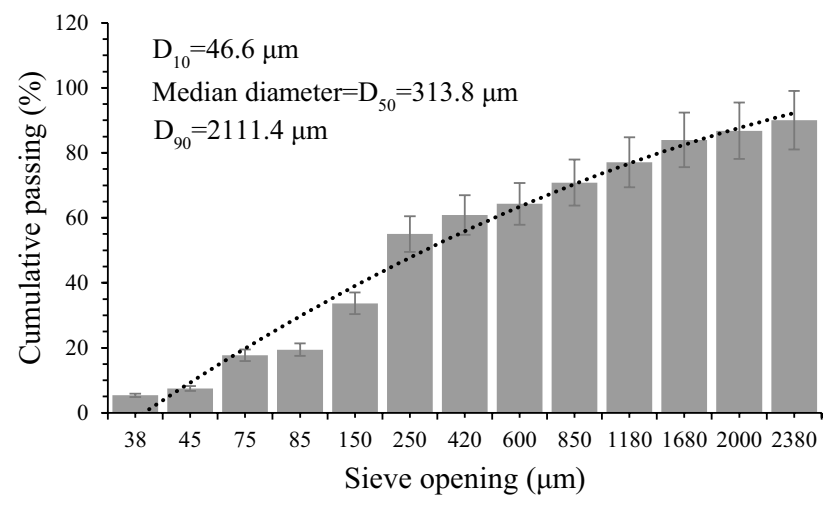

Fig. 2 Particle size distribution of AFT

precipitation, purification, re-precipitation, and finally calcination.

At first, particles of the waste were sieved to a size below $850 \mu \mathrm{m}$. Then, the sieved particles were washed with distilled water to remove soluble salts. In the next stage, the acidic leaching was performed using $5 \mathrm{M}$ hydrochloric acid with an acid-to-solid ratio of $10 \mathrm{ml} / \mathrm{g}$ for $90 \mathrm{~min}$. The leaching temperature was kept fixed at $80{ }^{\circ} \mathrm{C}$ using a water bath. In fact, this stage is at the heart of the extraction process, because the leaching time and temperature, acid concentration and amount of acid have significant effects on the dissolution of aluminum oxide that

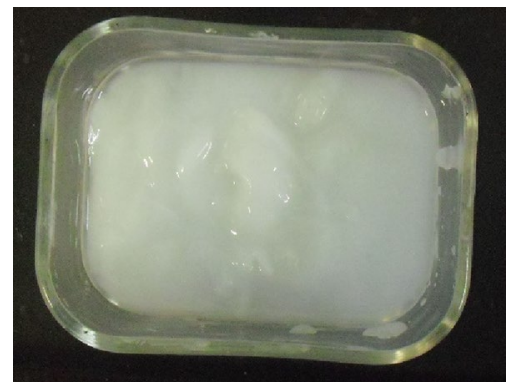

Fig. 4 The re-precipitated aluminum hydroxide

exists in the AFT. The resulting chloride solution at the end of this step was filtered using the filter papers of Whatman grade 41 and was sent to precipitation stage. At this stage, aluminum hydroxide precipitated from the solution by adjusting $\mathrm{pH}$ to the range of 5.5-6.5 using ammonia. Since the precipitated aluminum hydroxide may contain impurities such as divalent metal hydroxides (iron, magnesium, calcium, etc.), it was sent to purification stage for the separation of impurities. Purification was carried out by adjusting the $\mathrm{pH}$ to 12 by adding $2 \mathrm{~N}$ sodium hydroxide aqueous solution dropwise. The aluminum hydroxide gel (Fig. 4) was then re-precipitated from the resulting sodium aluminate solution by adding $2 \mathrm{M}$ ammonium nitrate solution.

The obtained aluminum hydroxide was rinsed using deionized water for several times and then dried in the oven at $110{ }^{\circ} \mathrm{C}$. The oven-dried sample was transferred to an alumina crucible and was eventually calcined at $800{ }^{\circ} \mathrm{C}$ for $2 \mathrm{~h}$ to obtain $\gamma$-alumina. The rate of the temperature increase in the furnace was $10{ }^{\circ} \mathrm{C} / \mathrm{min}$.

Figure 5 depicts the XRD pattern of aluminum hydroxide obtained in the re-precipitation stage.

As can be seen, aluminum hydroxide has precipitated as gibbsite and bayerite phases. The peaks have been identified based on standard cards of JCPDS-00-007-0324 and JCPDS-00-001-0287 for gibbsite and bayerite, respectively. Figure 6 illustrates the XRD pattern of the as-synthesized alumina after calcination of aluminum hydroxide. A comparison of the peaks with standard cards of JCPDS10-0425, ICDD-34-0493, and ICDD-04-0878 indicates

Fig. 3 Alumina extraction process from AFT

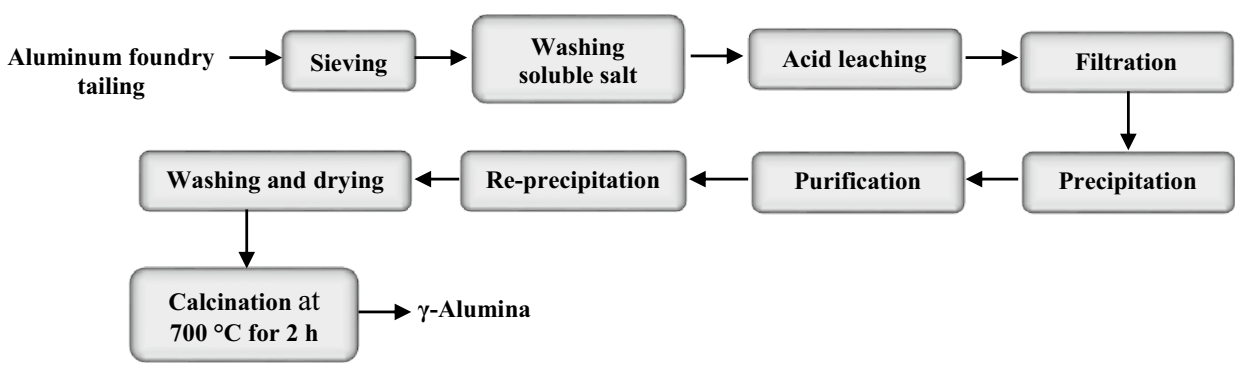




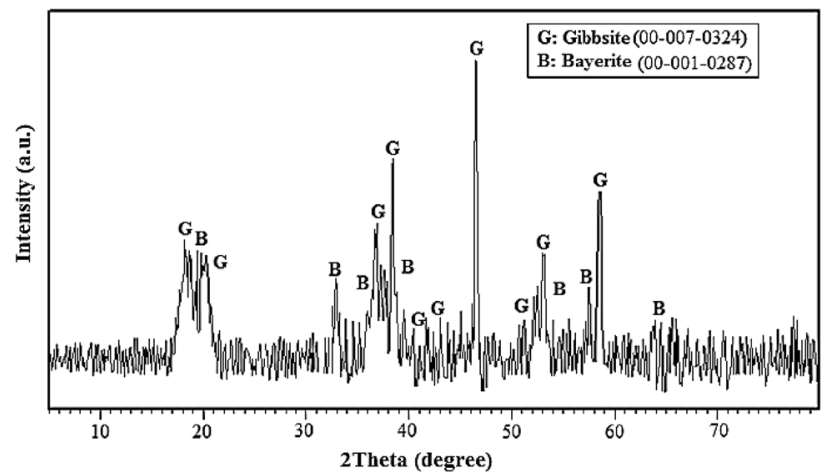

Fig. 5 XRD pattern of aluminum hydroxide obtained in re-precipitation stage

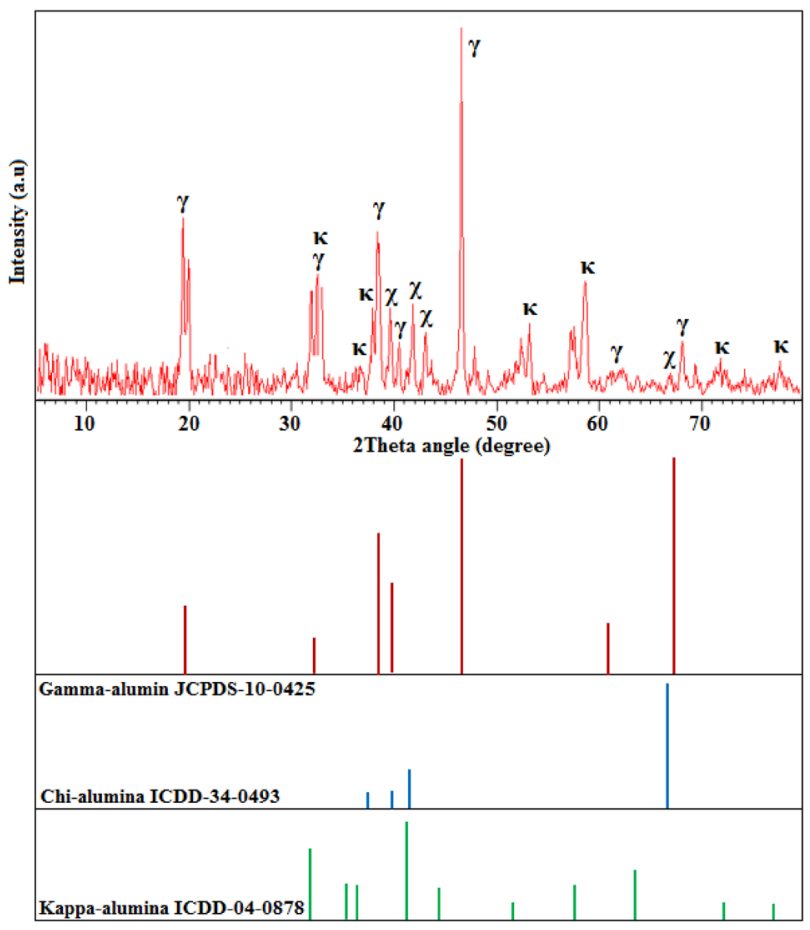

Fig. 6 XRD pattern of the as-synthesized $\gamma$-alumina

that the product obtained here contains majorly $\gamma$-phase as well as a small amount of $\chi$ and $\kappa$ phases.

The XRD patterns in both Figs. 5 and 6 exhibit line broadening. A line broadening is caused by the contribution of the crystallite size and microstrain in X-ray diffraction. Such contributions can be taken into account using Williamson-Hall equation [31]:

$B \cos \theta=0.9 \lambda / D+4 \varepsilon \sin \theta$

where $D$ is the average crystallite size, $\lambda$ the wavelength of the radiation $(\lambda=1.541874 \AA), \theta$ Bragg's angle, $B$ the full width at half maximum (FWHM), and $\varepsilon$ is strain. Terms $B$

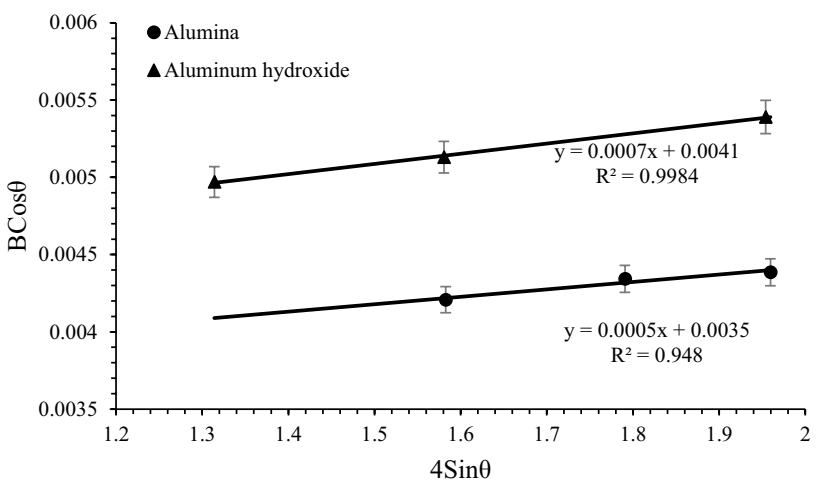

Fig. 7 Williamson-Hall plots for the as-synthesized aluminum hydroxide and $\gamma$-alumina

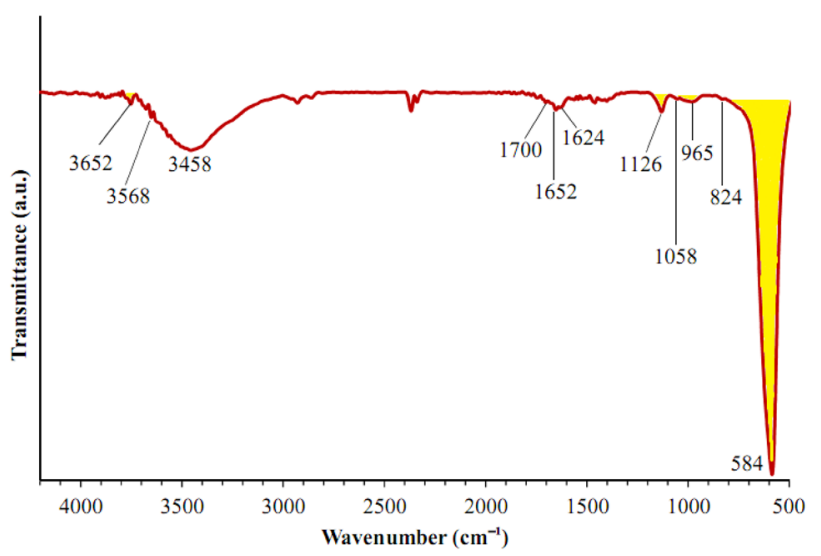

Fig. 8 FTIR spectrum of aluminum hydroxide obtained in re-precipitation stage

and $2 \theta$ were acquired from each XRD pattern using Panalytical X'Pert High Score Plus software which uses information of ICDD and JCPDS cards to recognize alumina phases. Figure 7 illustrates the plot of $B \operatorname{Cos} \theta$ against $4 \operatorname{Sin} \theta$ for the as-synthesized aluminum hydroxide and $\gamma$-alumina. The Y-intercepts involve the crystallite size. So, the average crystallite sizes of aluminum hydroxide and $\gamma$-alumina are 30.8 and $39.6 \mathrm{~nm}$, respectively.

Figure 8 indicates FTIR spectrum for the as-synthesized aluminum hydroxide obtained in re-precipitation stage.

The band appearing at wavenumber $3652 \mathrm{~cm}^{-1}$ is due to the stretching vibration of $\mathrm{Al}-\mathrm{OH}$. The bands at wavenumbers of 3568 and $34,358 \mathrm{~cm}^{-1}$ are attributed to the stretching vibration of $-\mathrm{OH}$ groups in the structure of hydration water. The band occurring at $1700 \mathrm{~cm}^{-1}$ is the result of stretching vibration of intermolecular interactions such as $\mathrm{OH}-\mathrm{O}$ hydrogen bonds which existed in polymeric species of $\mathrm{Al}_{3} \mathrm{O}_{4}(\mathrm{OH})_{28}^{3+}$ and $\left[\mathrm{AlO}_{4} \mathrm{Al}_{12}(\mathrm{OH})_{24}\left(\mathrm{H}_{2} \mathrm{O}\right)_{12}\right]^{7+}$. The absorption bands observed at 1652 and $1624 \mathrm{~cm}^{-1}$ are because of the bending vibration of $\mathrm{OH}$ groups in hydration water. 
The available bands at 1126 and $1058 \mathrm{~cm}^{-1}$ are the consequence of symmetrical bending vibration of $\mathrm{Al}-\mathrm{O}-\mathrm{H}$ group. The appearance of bands at wavenumbers of 965,824 , and $584 \mathrm{~cm}^{-1}$ is the results of bending vibration of $\mathrm{Al}-\mathrm{O}-\mathrm{Al}$, the existence of $\mathrm{AlO}_{4}$ group, and octahedral coordination of $\mathrm{AlO}_{6}$, respectively.

Table 2 presents the chemical composition of the assynthesized $\gamma$-alumina determined by XRF technique. As it is clear from Table 2, the as-synthesized alumina contains more than $97 \% \mathrm{Al}_{2} \mathrm{O}_{3}$, suggesting that it is suitable for catalyst and catalyst support applications.

Table 2 Chemical analysis of as-synthesized $\gamma$-alumina

\begin{tabular}{lr}
\hline Oxide & $\mathrm{Wt} \%$ \\
\hline $\mathrm{Al}_{2} \mathrm{O}_{3}$ & 97.61 \\
$\mathrm{SiO}_{2}$ & 0.58 \\
$\mathrm{CaO}$ & 0.38 \\
$\mathrm{Fe}_{2} \mathrm{O}_{3}$ & 0.12 \\
$\mathrm{MgO}$ & 0.64 \\
$\mathrm{SO}_{3}$ & 0.16 \\
$\mathrm{~K}_{2} \mathrm{O}$ & 0.08 \\
\hline
\end{tabular}

Figure 9 displays FESEM micrographs of aluminum hydroxide and $\gamma$-alumina and also corresponding EDAX elemental analyses.

Elemental analysis shows that the aluminum and oxygen are the main elements present in the as-synthesized products. However, the identification of hydrogen in the aluminum hydroxide is not possible by EDAX technique, since this technique can only detect elements with atomic number higher than 5. Figure 10 shows other FESEM images of the as-synthesized aluminum hydroxide and $\gamma$-alumina. As can be observed, both aluminum hydroxide and $\gamma$-alumina particles show strong agglomeration. This intensive tendency toward agglomeration has been reported in the literature [32]. From a morphological point of view, both $\gamma$-alumina and aluminum hydroxide particles have rounded-corner shapes. Enhancement of the size of alumina particles is due to the calcination process.

Figure 11 displays the TEM image of the as-synthesized $\gamma$-alumina at a magnification of $35 \mathrm{k} \times$. As seen, the aggregations have formed relatively sphere-shaped particles.

To test the repeatability and reproducibility of the proposed process, the average crystallite size and particle size distribution were taken into consideration. The average
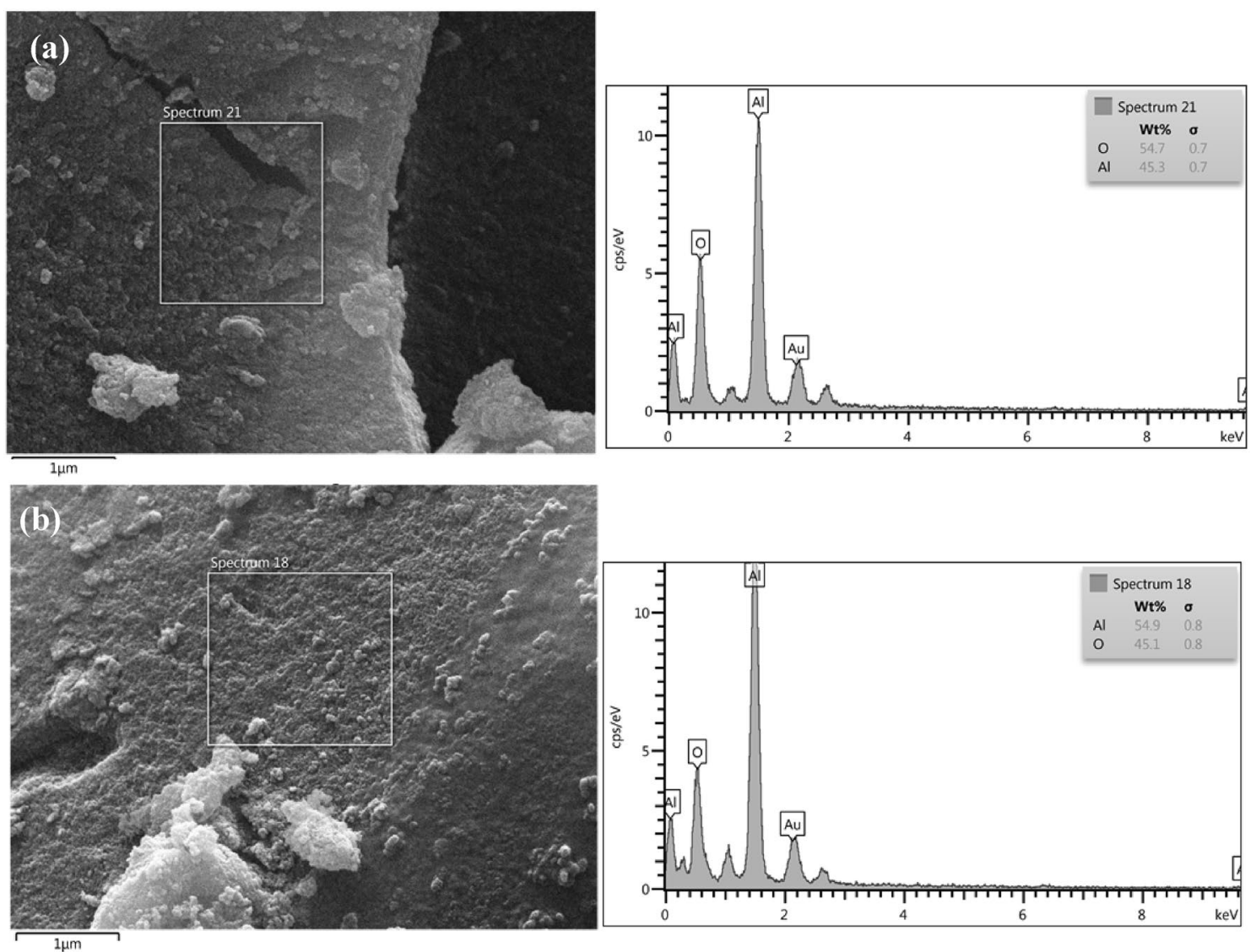

Fig. 9 FESEM micrographs and EDAX elemental analysis of $\mathbf{a}$ aluminum hydroxide and $\mathbf{b} \gamma$-alumina 


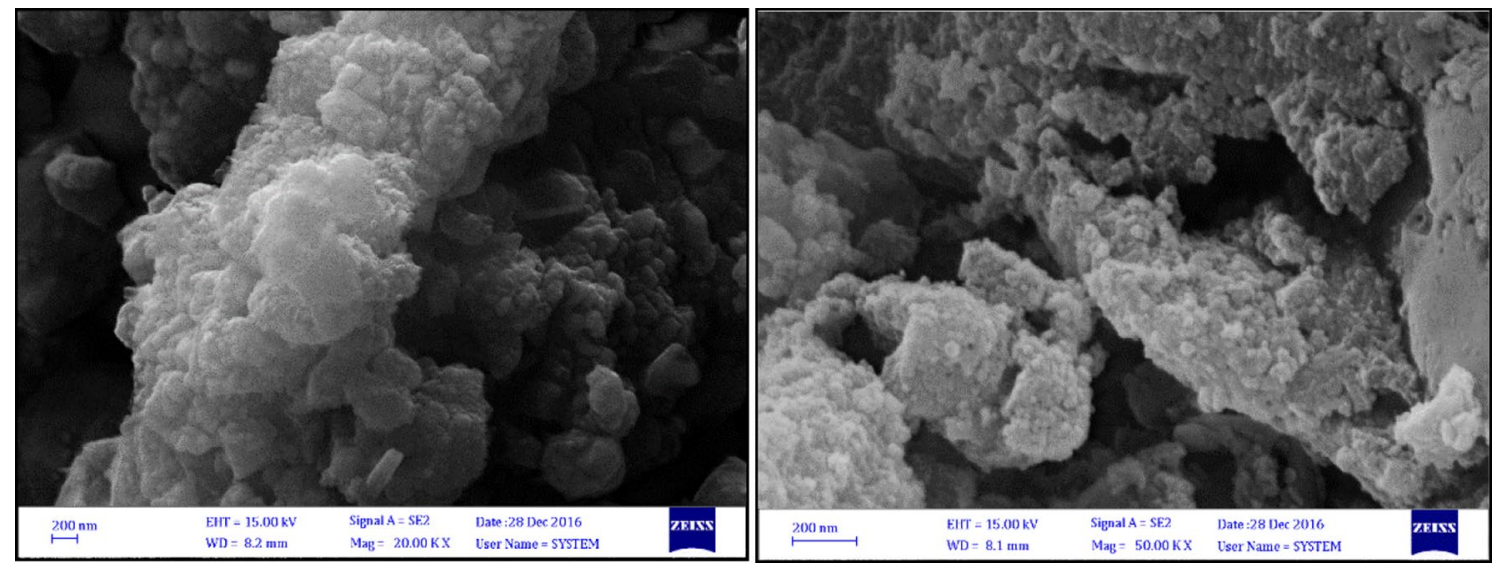

Fig. 10 FESEM image of the as-synthesized (Right) aluminum hydroxide and (Left) $\gamma$-alumina

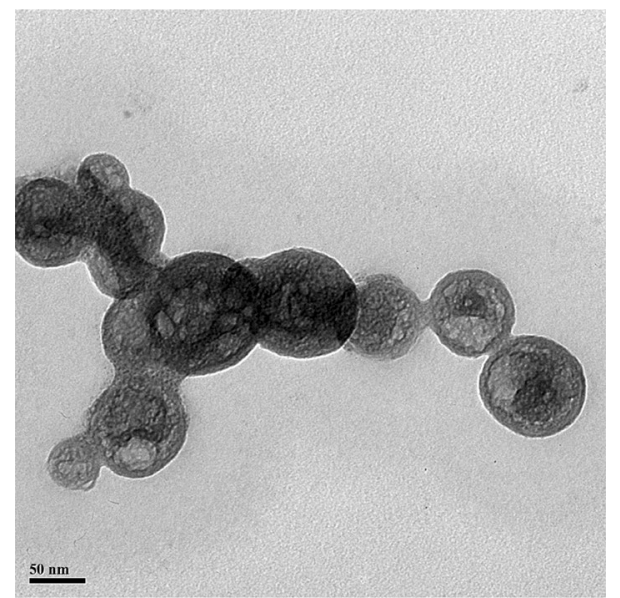

Fig. 11 TEM image of the as-synthesized $\gamma$-alumina

crystallite size was earlier discussed by presenting Fig. 7 . Figure 12 depicts the DLS particle size distributions of alumina products which have been synthesized from two separate trials of the extraction process. As can be clearly seen, both products exhibit a particle size distribution very similar to each other. Both average crystallite size and DLS analyses confirm the repeatability and reproducibility of the proposed process.

\section{Conclusions}

Nanostructured $\gamma$-alumina was successfully extracted from aluminum foundry tailing via an innovative hydrometallurgical process. The XRD pattern of the as-synthesized alumina showed majorly gamma-phase characteristic peaks. Quantitative calculations of XRD data revealed the nano-crystallinity of both synthesized aluminum hydroxide and alumina. The

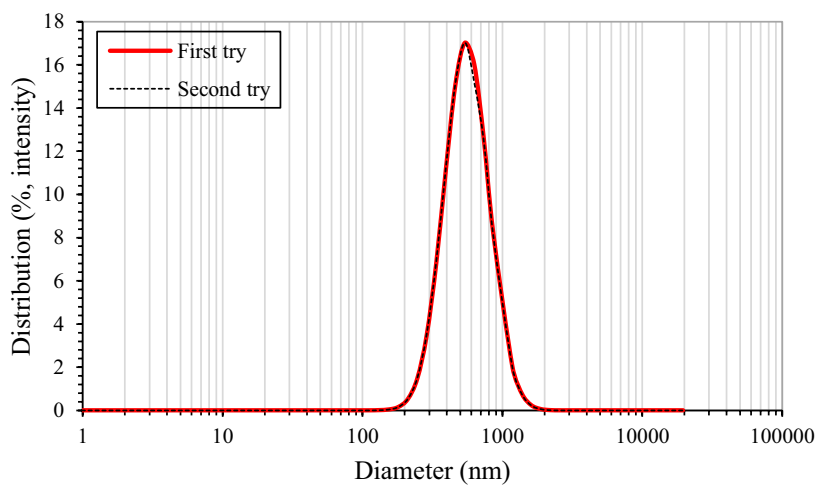

Fig. 12 Particle size distributions of the as-synthesized alumina products

chemical composition by XRF analysis revealed that the extracted alumina exhibits a high purity of more than $97 \mathrm{wt} \%$. The FESEM and TEM micrographs indicated that the as-synthesized products have rounded-corner shape with a tendency for strong agglomeration. Elemental analyses by EDAX technique confirmed the presence of $\mathrm{Al}$ and $\mathrm{O}$ as major chemistry. Taken together, all the results confirm the suitability of the as-synthesized $\gamma$-alumina for catalytic applications.

\section{Compliance with ethical standards}

Conflict of interest The authors declare no conflict of interest.

Open Access This article is distributed under the terms of the Creative Commons Attribution 4.0 International License (http://creativeco mmons.org/licenses/by/4.0/), which permits unrestricted use, distribution, and reproduction in any medium, provided you give appropriate credit to the original author(s) and the source, provide a link to the Creative Commons license, and indicate if changes were made. 


\section{References}

1. Singh, J., Laurenti, R., Sinha, R., Frostell, B.: Progress and challenges to the global waste management system. Waste Mang Res 32(9), 800-812 (2014)

2. Adeosun, S.O., Sekunowo, O.I., Taiwo, O.O., Ayoola, W.A., Machado, A.: Advances in materials physical and mechanical properties of aluminum dross. Adv Mater 3(2), 6-10 (2014)

3. Das, B.R., Dash, B., Tripathy, B.C., Bhattacharya, I.N., Das, S.C.: Production of $\eta$-alumina from waste aluminium dross. Miner Eng 20, 252-258 (2007)

4. Mahinroosta, M., Allahverdi, A.: Hazardous aluminum dross characterization and recycling strategies: a critical review. J Environ Manag 223, 452-468 (2018)

5. Zhou, Y., Wu, L., Wang, J., Wang, H., Dong, Y.: Alumina extraction from high-alumina ladle furnace refining slag. Hydrometallurgy 140, 14-19 (2013)

6. Colman, B.P., Espinasse, B., Richardson, C.J., Matson, C.W., Lowry, G.V., Hunt, D.E., Wiesner, M.R., Bernhardt, E.S., Murphy, C.J.: Emerging contaminant or an old toxin in disguise? Silver nanoparticle impacts on ecosystems. Environ Sci Technol 48, 5229-5236 (2014)

7. Shukla, A.K., Iravani, S.: Metallic nanoparticles: green synthesis and spectroscopic characterization. Environ Chem Lett 15(2), 223-231 (2017)

8. Amirjani, A., Bagheri, M., Heydari, M., Hesaraki, S.: Label-free surface plasmon resonance detection of hydrogen peroxide; a bioinspired approach. Sens Actuators B 227, 373-382 (2016)

9. Filippo, E., Manno, D., Buccolieri, A., Serra, A.: Green synthesis of sucralose-capped silver nanoparticles for fast colorimetric triethylamine detection. Sens Actuators B 178, 1-9 (2013)

10. Bollella, P., Schulz, C., Antiochia, R., Favero, G., Mazzei, F., Ludwig, R., Gorton, L.: Green synthesis and characterization of gold and silver nanoparticles and their application for development of a third generation lactose biosensor. Electroanalysis 28 , $1-11(2016)$

11. Mahinroosta, M., Allahverdi, A.: A promising green process for synthesis of high purity activated-alumina nanopowder from secondary aluminum dross. J Clean Prod 179, 93-102 (2018)

12. Mahinroosta, M., Allahverdi, A.: Enhanced alumina recovery from secondary aluminum dross for high purity nanostructured $\gamma$-alumina powder production: kinetic study. J Environ Manag 212, 278-291 (2018)

13. Yusoff, M.S.M., Muslim, M., Paulus, W (2009) A waste to wealth study on converting aluminium dross schedule waste into $\gamma$ and $\alpha$ alumina. Proceedings of the 7th WSEAS International Conference on ENVIRONMENT, ECOSYSTEMS and DEVELOPMENT (EED ‘09), Tenerife, Canary Islands, Spain

14. Dash, B., Das, B.R., Tripathy, B.C., Bhattacharya, I.N., Das, S.C.: Acid dissolution of alumina from waste aluminium dross. Hydrometallurgy 92, 48-53 (2008)

15. Sarker, S.R., Alam, Z., Qadir, R., Gafur, M.A., Moniruzzaman, M.: Extraction and characterization of alumina nanopowders from aluminum dross by acid dissolution process. Int J Miner Metall Mater 22(4), 429-436 (2015)

16. Huiquan, L., Junbo, H., Chenye, W., Weijun, B., Zhenhua, S.: Extraction of alumina from coal fly ash by mixed-alkaline hydrothermal method. Hydrometallurgy 147-148, 183-187 (2014)

17. Abdul Wahab, A.A., Suhair, Z.A., Wasan, A.M., Malath, Q.A., Mohammed, K.H., Falah, A.J.: Extraction of alumina from Iraqi colored kaolin by lime-sinter process. Iraqi Bull Geol Min 10(3), 109-117 (2014)

18. Pedersen, H.: Process of manufacturing aluminum hydroxide. US Patent 1,618,105, 15-02-1927

19. Bansiwal, A., Pillewan, P., Biniwale, R.B., Sadhana Rayalu, S.: Copper oxide incorporated mesoporous alumina for defluoridation of drinking water. Microporous Mesoporous Mater 129, 54-61 (2010)

20. Hao, J., Han, M., Wang, C., Meng, X.: Enhanced removal of arsenite from water by a mesoporous hybrid material-thiolfunctionalized silica coated activated alumina. Microporous Mesoporous Mater 124, 1-7 (2009)

21. Lee, G., Chen, C., Yang, C., Ahn, W.: Enhanced adsorptive removal of fluoride using mesoporous alumina. Microporous Mesoporous Mater 127, 152-156 (2010)

22. Abbas, A., Mohammad, S.T., Hasan, B.: Simultaneous removal of heavy-metal ions in wastewater samples using nano-alumina modified with 2,4-dinitrophenylhydrazine. J Hazard Mater 181, 836-844 (2010)

23. Wei, W., Zhijian, W., Wan, C., Mingming, Z., Dongke, Z.: Synthesis of mesoporous alumina with tunable structural properties. Microporous Mesoporous Mater 217, 12-20 (2015)

24. Ebrahimi-Basabi, M., Javadpour, J., Rezaie, H., Goodarzi, M.: Mechanochemical synthesis of alumina nanoparticles. Iran J Mater Sci Eng 6(1), 26-30 (2009)

25. Hyun, C.L., Hae, J.K., Chang, H.R., Kyung, H.L., Jae, S.L., Soo, H.C.: Synthesis of nanostructured $\gamma$-alumina with a cationic surfactant and controlled amounts of water. Microporous Mesoporous Mater 79, 61-68 (2005)

26. Mirjalilia, F., Hasmalizab, M., Chuah Abdullah, L.: Size-controlled synthesis of nano $\alpha$-alumina particles through the sol-gel method. Ceram Int 36(4), 1253-1257 (2010)

27. Potdar, H.S., Ki-Won, J., Jong, W.B., Seung-Moon, K., Yun-Jo, L.: Synthesis of nano-sized porous $\gamma$-alumina powder via a precipitation/digestion route. Appl Catal A Gen 321(2), 109-116 (2007)

28. Norouzbeigi, R., Edrissi, M.: Preparation of nano alumina powder via combustion synthesis: porous structure optimization via Taguchi L16 design. J Am Ceram Soc 94(11), 4052-4058 (2011)

29. Yu, A.K.: Electric explosion of wires as a method for preparation of nanopowders. J Nanoparticle Res 5(5-6), 539-550 (2003)

30. Saša, L., Ivan, S., Stevan, O., Vladimir, V.S.: Chemical vapour synthesis and characterisation of $\mathrm{Al}_{2} \mathrm{O}_{3}$ nanopowders. Ceram Int 41, 3653-3658 (2015)

31. Williamson, G.K., Hall, W.H.: Discussion of the theories of line broadening. Acta Metall 1, 22 (1953)

32. Pirhadi Tavandashti, M., Zandrahimi, M., Akbari, B.: Agglomeration assessment of nano-sized alumina powders. Iran J Mater Sci Eng 6(1), 15-19 (2009)

Publisher's Note Springer Nature remains neutral with regard to jurisdictional claims in published maps and institutional affiliations. 